www.jmscr.igmpublication.org

Impact Factor 5.84

Index Copernicus Value: 83.27

ISSN (e)-2347-176x ISSN (p) 2455-0450

crossref DOI: _https://dx.doi.org/10.18535/jmscr/v5i8.48

\begin{abstract}
Journal Of Medical Science And Clinical Research
IGM Publication

An official Publication of IGM Publication
\end{abstract}

\title{
Children and Mobile Media devices
}

\author{
Authors \\ Dr Sayid M Barkiya ${ }^{1}$, Dr Damodaran Alakkodan ${ }^{2}$ \\ ${ }^{1}$ Professor of Paeditrics, Kannur Medical College \\ ${ }^{2}$ Associate Professor of Pediatrics, Kannur Medical College
}

\begin{abstract}
Introduction: The mobile phone is a symbol of growing up for children. The use of interactive screen media such as smartphones and tablets by children is increasing rapidly.

Aim \& Objectives: a)To find out the time spent by children on Mobile Media Devices (MMD) b)To Identify their preferences and to review the existing literature and suggest preliminary guidance for parents and families.

Study Design: cross -sectional study. setting: kannur

Materials \& Methods: A cross sectional study was conducted at Kannur medical college kannur from April 2015 to October 2015 and study includes 300 children, and age group between 3- 10 years, comprising of both girls and boys hailing from rural and urban areas of Kannur district in kerala were interviewed to find out their mobile media device using and their preferences.

Results: The data was analysed statistically. Results on average children of the present study spent time is about 30-45 minutes per day in children age group between 3-6 years old and 2-3 hours per day in children age group between 7-10 respectively. Most of them $87 \%$ are using smartphone handset and surprisingly there is no difference between girls and boys. Apparently urban children spend more time on mobile Media devices than their rural counterparts., their preferences are in the order of while feeding especially during their meals $90 \%$ in toddler and Preschool children, followed by calling $45 \%$, send message $50 \%$, access mobile internet $80 \%$ whats up messages $33.6 \%$. songs $21.5 \%$, camera $90 \%$, music players 60\%, movies players 70\%, Download apps 70\%, social net working $50 \%$,profile set to public 40\%, come with new friends on line 15\%,parents concern about child mobile use $100 \%$, sports $13.7 \%$, serials $12.9 \%$ news $9.2 \%$ cartoons $6.5 \%$ others $0.3 \%$. Parental concerns and mobile safety Concerns about children's privacy is lowest and $83 \%$ of parents are "very concerned" or "somewhat concerned" about their children's privacy on mobile phones. 85\% of families do not set rules on mobile phone use. Our study age betwen 5-7 years children only 27\% had abnormal behaviour and $4 \%$ in age group between 8-10 years. respectively. When compared to children had less sleep in 26.6\% between 5-7 years and $8.3 \%$ in 8 -10 years of age.

Conclusion: The children of the study spend more time on entertainment programms. Studies across different parts of the country have shown that children view entertainment programs more than educational and informative ones. The children age group between 3-6 years were using mobile during their meals. A recently published data concurs with the present observation. Our study age betwen 5-7 years children only 27\% had abnormal behaviour and $4 \%$ in age group between 8 10 years. respectively. compared to children had less sleep in 26.6\% between 5-7 years and 8.3\% in 8-10 years of age.

Children programm have become synonymous with foriegn cartoon films and educational programm have received set back. Since mobile hand set is considered more than a foster parent using should be viewed seriously. Programms related to children should be introduced to improve their educational and health aspects. Accordingly policy makers should take steps to implement this. Children are viewed as a medium for promoting consumerism. marketing company do not appear to be very concerned about the impact on mobile viewership of children. Highly developed academic bodies in our country hardly pay any attention to children's programme. parents and teachers need to consider it their responsibility to ensure over usage and certain viewing discipline.

Keywords: preschool children; mobile phones; relationship.
\end{abstract}




\section{Introduction}

Children being addicted to their mobile media devices and it seems to be the common complaint of most metropolitan parents in India today. A recent consumer lab research report conducted by Ericsson states that of the 69 million children under the age of 18 residing in urban cities, 30 million have a personal handset and 11 million share it with one of their family members, while 28 million have no access to it. With landline phones all but phased out worldwide, it is no surprise to see toddlers and pre-schoolers being allowed to use (and usually master) their parents' electronic despite the uneven spread of broadband internet in India, the love for smartphones and other hand-held electronic devices has exploded across nearly every sphere of life, and overturned ultimately, the way we behave. Mobile phones have become a widespread phenomenon in the present time. These pocket-sized tools are no less than a mini computer. They can do anything from a standard phone call to surf the internet. Not just the adults, this technology is affecting the kids as well. Recent suggestions that a limited amount of educational interactive media use may be acceptable for children aged less than 2 years. ${ }^{[1]}$ as videophone apps are just as effective as reallife encounters in teaching language to 24 month olds, Mobile devices such as smartphones and tablets are important part in children's lives. ${ }^{[2]}$ Depending on how they are used, mobile devices could have both positive and negative impacts on family interactions. ${ }^{[3]}$ According to Common Sense Media's nationwide survey, $72 \%$ of children ages 0 to 8 years used a mobile device in 2013, up from 38\% in 2011.Even more dramatic was the increase in the use by children ,2 years old: $38 \%$ in 2013 , up from $10 \%$ in 2011 . Despite an overall increase in access, the 2013 Common Sense Media survey found a large disparity in access to mobile devices and apps among lowincome and minority children. research on the use of mobile devices by young children is lagging behind its adoption. The American Academy of Pediatrics' policy recommendation to "discourage the use of media by children under the age of two"1 was drafted before the introduction of tablets in $2010 .{ }^{[4]}$ the objectives of the study was to examine exposure and use of mobile media devices by young children in an urban, low social economic class family in aspect of Age of first mobile usage, Reasons for getting a mobile devices and their preferences. Parents' concerns over their children's use of mobile phones.

\section{Methods \\ Participants}

A total of 300 children including their parents or caregivers were participated in the study but only 200 ( $\mathrm{N}=$ Total number of participants in the study, $n=$ subset as per gender) were used for analysis due to insufficient data and/or part completed information. All participants were KG and to lower primary school students from a Secondary State High School $(n=300)$. Students' ages ranged from 3 to 10 with a mean age of 7 . This High School is located within a low-social economic area within the kannur district, kerala.

\section{Design \\ Data Analysis}

Data were analysed through the Statistical Package for the Social Sciences (SPSS) to report on statistical significance. Several descriptive tests were performed to investigate demographic details in terms of saliency. Further correlation analyses was performed to explore how two variables were related and to what extent they explained the direction of the relationship.

\section{Study Setting and Study Sample}

We conducted a cross-sectional study with a convenience sample of parents of children 3 years to 10 years of age who made a well or sick visit between April 2015 to October 2015. To a pediatric outpatient for health check up at kannur medical college hospital,. To the parents of these children a questionnaire was given regarding reason for getting mobile, how many minutes or hours they are spending on mobile devices, what 
is their preferences, how they feel after getting mobile, age of first mobile ownership, parent are concern over their children's use of mobile, other questions regarding warning signs of any abnormal behaviour or not able to sleep. Pediatric guidelines specifically regarding mobile device use by young children have not yet been formulated, other than recent suggestions that a limited amount of educational interactive media use may be acceptable for children aged, 2 years ${ }^{(1)}$ Promising research suggests that interactive media such as learn-to-read apps and electronic books (ebooks) may increase early literacy skills by providing practice with letters, phonics, and word recognition. E-books can be useful in promoting vocabulary development and reading comprehension and could be more engaging for young children via digital scaffolds (eg, oral narration, synchronous text highlighting, and embedded sound effects, animations, or games). However, such extraneous e-book enhancements have also been shown to distract children's attention from the story and to interfere with comprehension.3 In other words, the visual design, sound effects, and touch screen interface of interactive media can either engage young children or distract them from educational content. A balance between is necessary to facilitate learning. smartphones and tablets are increasingly used to help distract children during anesthesia induction or medical/surgical procedures. ${ }^{(5)}$ Parents' use of interactive media also has the potential to distract from parent-child interactions. Parent media use usually involves work, errands, or social or other content requiring significant information processing, which makes it harder to balance attention between devices and managing child behavior. ${ }^{(6)}$ Existing research is limited, and many questions remain, such as Mobile and interactive media have great potential to promote learning through joint engagement between caregivers and children, by demonstrating ideas for parent-child activities, or by modeling teaching strategies (eg, dialogic reading, phonetic, or sound blending skills) with which low-literacy parents may not be familiar.

\section{Results}

Children and parents were presented with different questionnaires that followed the same themes, allowing for direct comparisons to be drawn on key areas. between 3 to 10 years, and their guardians.65\% of all children surveyed currently use a mobile phone; of those, $81 \%$ have a new handset. 10 is the most common age for children to get their first mobile phone. $27 \%$ of child mobile phone owners have a smartphone. Children's smartphone ownership in India and Indonesia is double that of their parents. Children whose parents own smartphones or feature phones are more likely to have one also. Tablet use is relatively low with only $18 \%$ penetration in Egypt and Chile, $7 \%$ in Indonesia and between 5-7\% in Japan and India.

\section{Daily media use by children}

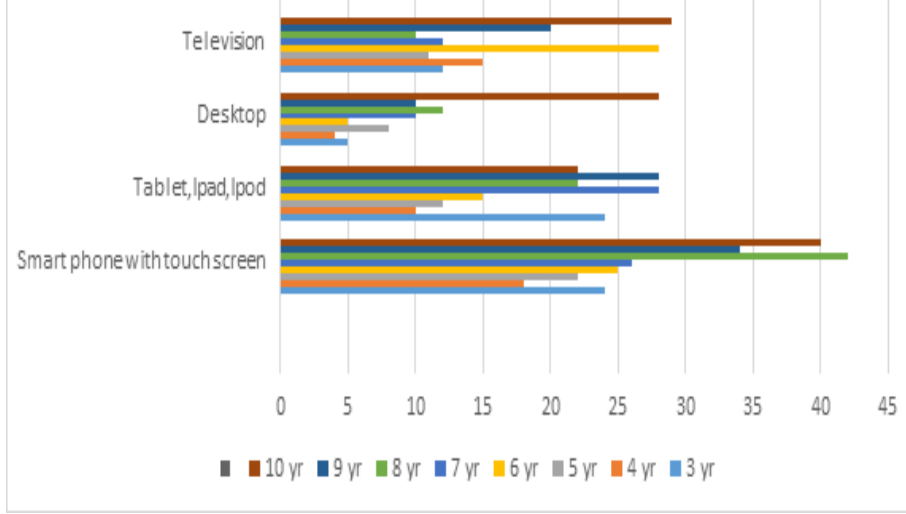

1 Observation and Characteristics

$\mathrm{n}$

$(\%)$

Day of the week

Weekday

$200 \quad(66.7)$

Weekend

$100 \quad(50)$

Mealtime

Lunch (11:30 AM - 2:00 PM)

$160 \quad(53.3)$

Midafternoon (2:00 - 4:00 PM)

$40 \quad(13.3)$

Dinner (4:00 - 7:00 PM )

$100 \quad(33.3)$

Estimated child ages 3-5 years

5-7 years

$8-10$ years 


\begin{tabular}{|l|c|c|}
\hline Time in mnts & no. of cases & percentage \\
\hline$\leq 30$ & 140 & 47 \\
\hline $31-60$ & 66 & 22 \\
\hline $61-120$ & 51 & 17 \\
\hline$\geq 121-300$ & 43 & 14 \\
\hline Total & 300 & 100 \\
\hline
\end{tabular}

\begin{tabular}{|c|c|c|}
\hline $\begin{array}{l}\text { number of } \\
\text { messages }\end{array}$ & $\begin{array}{l}\text { t per day } \\
\text { number }\end{array}$ & Percentage \\
\hline 0 & 17 & 6 \\
\hline $1-5$ & 58 & 19 \\
\hline $6-10$ & 55 & 16 \\
\hline $11-20$ & 65 & 22 \\
\hline$>20$ & 112 & 37 \\
\hline Total & 300 & 100.0 \\
\hline
\end{tabular}

time of maximum use

\begin{tabular}{|l|c|c|}
\hline \multicolumn{1}{l}{ time } & number & percentage \\
\hline Morning & 23 & 8 \\
\hline Afternoon & 12 & 4 \\
\hline Evening & 121 & 40 \\
\hline Night & 144 & 48 \\
\hline Total & 300 & 100.0 \\
\hline
\end{tabular}

Mode of use

\begin{tabular}{|l|c|c|}
\hline mode & number & percentage \\
\hline Ringing & 133 & 44.4 \\
\hline Vibrating & 112 & 37.3 \\
\hline Silent & 54 & 18 \\
\hline Switch off & 1 & 0.3 \\
\hline Total & 300 & 100.0 \\
\hline
\end{tabular}

time spent on other features

\begin{tabular}{|l|c|c|}
\hline \multicolumn{1}{l}{ time } & number & percentage \\
\hline$<1 \mathrm{hr}$ & 66 & 44 \\
\hline $1-2 \mathrm{hrs}$ & 24 & 22 \\
\hline$>2 \mathrm{hrs}$ & 77 & 8 \\
\hline don't use at all & 300 & 26 \\
\hline Total & & 100.0 \\
\hline
\end{tabular}

use at Place/situation

\begin{tabular}{|l|c|c|}
\hline place & number & percenatge \\
\hline Classroom & 2 & 0.6 \\
\hline Library & 162 & 54 \\
\hline Eating & 125 & 42. \\
\hline Driving & 10 & 3.4 \\
\hline TOTAL & 300 & 100 \\
\hline
\end{tabular}

\begin{tabular}{|l|c|c|}
\hline Abnormal behaviour \\
\hline age in years & total number & percentage \\
\hline $3-5$ & 205 & 68.3 \\
\hline $5-7$ & 83 & 27.6 \\
\hline $8-10$ & 12 & 4 \\
\hline TOTAL & 300 & 100 \\
\hline
\end{tabular}

\section{Disturbed in sleep}

\begin{tabular}{|l|c|c|}
\hline age in years & total number & percentage \\
\hline $3-5$ & 195 & 65 \\
\hline $5-7$ & 80 & 26.6 \\
\hline $8-10$ & 25 & 8.3 \\
\hline TOTAL & 300 & 100 \\
\hline
\end{tabular}

Children's use of mobile phones Initially, children use their mobile phone predominantly for calling; however, as they get older, messaging becomes the preferred choice of communication. Nearly $24 \%$ and $20 \%$ of children in Indonesia and India respectively, send over 51 messages a day. 54\% of all child mobile phone users access the mobile internet; this increases to over $87 \%$ when looking exclusively at smartphone users. $70 \%$ of all children who use the internet through their phone access it at least once a day. $11 \%$ of child mobile phone users surveyed list their handset as their primary device for accessing the internet; this increases to almost $32 \%$ among smartphone users. Cameras are the most used pre-installed function on mobiles (75\%) followed by music players $(60 \%)$ and movie players (50\%). Apps, social networking and other services Of those children who access the internet via their mobile phone, 57\% download or use apps; this is highest in Chile (78\%) and lowest in Egypt (44\%). Across all countries, entertainment apps are the most popular among children. Entertainment is the only category of apps that children use more than their parents across all countries. Information apps have the greatest increase in use as children get older, starting at $36 \%$ use for 8 -year-olds and rising to $67 \%$ at age 10. Although entertainment apps are the most popular, they are the only app category to decline from 90 to $77 \%$ at age $10.49 \%$ of children who access the internet via a mobile phone use it for social networking. $45 \%$ of thesey have their profiles set to public; this is as high as $55 \%$ among 10 -year olds. $70 \%$ of children have met or started to communicate with 'new friends' online.

In our study the adverse effects of mobile usage in children age between 3-5 years 68\% developed abnormal behaviour in the form of excessive crying and $65 \%$ children had decrease sleep in the night hours

Our study age between 5-7 years children only $27 \%$ had abnormal behaviour and $4 \%$ in age group between 8-10 years. respectively. When compared to children had less sleep in $26.6 \%$ 
between 5-7 years and 8.3\% in 8-10 years of age. the visual design, sound effects, and touch screen interface of interactive media can either engage young children or distract them from educational content ${ }^{[5]}$

smartphones and tablets are increasingly used to help distract children during anesthesia induction or medical/surgical procedures. the use of mobile media to occupy young children during daily routines such as errands, car rides, and eating out [6]

\section{Mostly use phone for}

\begin{tabular}{|l|c|c|c|c|}
\hline usage & Male & Female & Sum & Total \\
\hline mostly use phone & $N$ & $N$ & $n$ & $\%$ \\
\hline Calls & 38 & 41 & 79 & 26.3 \\
\hline Text & 37 & 34 & 71 & 24 \\
\hline Internet/email & 6 & 5 & 11 & 4 \\
\hline Video players & 12 & 13 & 25 & 8.3 \\
\hline Games & 11 & 18 & 29 & 9.6 \\
\hline MP3/music & 10 & 13 & 23 & 7.6 \\
\hline Camera & 30 & 32 & 62 & 21 \\
\hline
\end{tabular}

The ability of mobile media to effectively distract and entertain young children is also a potential benefit of their use. Indeed, smartphones and tablets are increasingly used to help distract children during anesthesia induction or medical/surgical procedures. ${ }^{[7]}$ Parents' use of interactive media also has the potential to distract from parent-child interactions. Parent media use usually involves work, errands, or social or other content requiring significant information processing, which makes it harder to balance attention between devices and managing child behavior. ${ }^{[8]} 1$ On the other hand, videophone apps may enhance interpersonal connections by allowing children to maintain face-to face interactions with distant family members. ${ }^{[9]}$ Over $70 \%$ of parents have concerns about children's mobile phone use, with viewing inappropriate sites and overuse sharing the highest percentage at around $82 \%$. Parents whose children use social networking sites are no more concerned about privacy than those whose children don't. $65 \%$ of all parents surveyed set rules on their children's mobile phone use, but there was no common response to rule-breaking across all countries. ${ }^{[10]}$.
Over $54 \%$ of parents who have access to parental control solutions use them; content filters are the most popular control method at $57 \%$. Almost $67 \%$ of parents believe that an adult in the family should educate their children about mobile phone use; this is a consistent preference across all countries. ${ }^{[11]}$ Mobile technology and children's wellbeing Nearly $80 \%$ of children surveyed say that having a mobile phone increases their confidence; thiks is particularly prevalent among children aged $10-13$ above $80 \%$. $63 \%$ of all children surveyed feel insecure without their mobile phones; this rises significantly in children aged 16-18 (66-71\%). Despite the popularity of mobile phones, children still talk face-to-face with their parents more than they call or message them. $90 \%$ of children who use social networking services on their mobile phone agree that these services reinforce relationships with close friends. India Mobile phone ownership rate Although only $50 \%$ of children exclusively own a mobile phone this increases to $93 \%$ when taking shared ownership into account. ${ }^{[12]}$ Just $36 \%$ of child mobile phone users have smartphones. Use of mobile phones $40 \%$ of children and $80 \%$ of parents use the calling function only; call frequency is particularly high among children with $74 \%$ making six or more calls a day. The use of messaging is popular with $85 \%$ of children sending 11 or more messages and nearly $55 \%$ of children sending over 50 . Mobile internet $88 \%$ of child mobile phone users access the internet via mobile phones. Mobile apps use $94 \%$ of children with access to handsets use apps; this is higher than thier parents usage at $65 \%$. Entertainment apps are used most at $91 \%$, followed by education and learning apps at $80 \%$. Social networking on mobile phones and privacy $66 \%$ of all children who access the internet via their mobile use social networking sites. $60 \%$ of children who use social networks have their profile set as open to the public while $70 \%$ have set their profile as private. Parental concerns and mobile safety Concerns about children's privacy is lowest and $83 \%$ of parents are "very concerned" or "somewhat 
concerned" about their children's privacy on mobile phones. $85 \%$ of families do not set rules on mobile phone use.

\section{Discussion}

Mobile media has had a clearly documented impact, both positive and negative, on children. Mobile devices, because of their portability and interactive components, are introducing media into all aspects of children's experience and deserve serious attention and research ${ }^{[13]}$ Until more is known, pediatric providers can offer guidance on preserving quality, connected family interactions, whether through "unplugged time" or a designated family hour, and how to establish healthy childhood media habits from early childhood. Overwhelmingly, the current study showed that children aged between 8 and 10 used their mobile phones most frequently for socialisation with the main use being to stay in contact with friends similar study done by Auter et al ; Boneva et al., ;similar study done by Green \& Singleton, Peterson, Most importantly mobiles phones seem to fulfil a fundamental need to communicate and to be connected with peers as most of the participants ${ }^{[14]}$

In our study the adverse effects of mobile usage in children age between 3-5 years 68\% developed abnormal behaviour inthe form of excessive crying and $65 \%$ children had decrease sleep in the night hours

Our study age betwen 5-7 years children only $27 \%$ had abnormal behaviour and $4 \%$ in age group between 8-10 years. respectively. When compared to children had less sleep in $26.6 \%$ between 5-7 years and 8.3\% in 8-10 years of age.

Australian Educational Computing, concluded in their study in 2014,. reported that they used their mobile phones to have conversations either as voice calls or more preferably as text messages, with a majority of them occurring over the weekends However, the study did find that both male female participants used their phones more frequently for calling and messaging others, listening to music and as a camera. These findings confirm the notion stated by Green and Singleton that males and females are likely to use mobile for social purposes as the female participants indicated that they used their mobile phones as a way of sharing and interacting with others rather than a device to make calls on ${ }^{[15]}$ In addition, the study found that students often receive their first mobile phone in the primary school years, There is a growing importance to study the use and impact of mobile phone use, particularly older children in order to understand and predict future technology use and perhaps more importantly to understand and assist children understand themselves and their communication and socialisation patterns.

\section{Mobile Phone Safety For Kids}

As a parent, you must take preventive measures to minimize your child's exposure to the harmful effects of mobile phones. As with mobile, it is crucial to ask how parents decide which technology and content is best for their children and how they monitor and set rules for use.

These include: Do not give cell phone if your child is under 16 years. A child's brain is too sensitive to withstand the effects of mobile radiation. Do not let your child hold a mobile phone directly up to his head. Use an air-tube headset instead. Do not let your child make calls in buses, trains, cars, and elevators. The mobile phone works harder to get the signal out through the metal, which increases the power level. Do not let your child use cell phone when the signal is weak. It will increase the power to the maximum, as the phone attempts to connect to a new relay antenna. Limit the use of cell phone around children. Make sure that there is no mobile phone mast or network tower near your home or your kid's school. Do not let children take mobile phones to school. Do not leave mobile phones in your children's bedroom at night.

\section{Conclusion}

This study found that mobile phone use amongst preschool children are high and widespread. There 
is a growing importance to study the use and impact of mobile phone use, particularly amongst schoolgoing children in order to understand and predict future technology use and perhaps more importantly to understand and assist older children understand themselves and their communicaktion and socialisation patterns. As mobile phones become ever more complex (integrating multimedia applications "APPS") the attraction to use them is likely to increase further and this will have an impact on how individuals communicate and socialise not only with others but also with the technology itself. Importantly, it should be noted that mobiles seem to aid or assist in the process of individualisation but it alone cannot explain how children come to the process of self-formation through communication.

\section{References}

1. Mobile and Interactive Media Use by Young Children: The Good, the Bad, and the Unknown Jenny S. Radesky, MD, Jayna Schumacher, MD, Barry Zuckerman, MD PEDIATRICS Volume 135, number 1, January 2015

2. Dr J-F, Dr Darren Pullen, and Dr Karen Swabey University of Tasmania, Australia Australian Educational Computing, 2014, 29(1).15 JETRO, Market and its opportunity in India, March, 2012, pp.12-15

3. JETRO, Delhi \& Mumbai Style, 2011, p.63

4. UNESCO-UIS/OECD, Education Trends in Perspective: Analysis of the World Education Indicators, OECD, 2005, pp.120-121.

5. OECD, OECD Economic Surveys: INDIA, 2011, pp.156-158.

6. JETRO, BOP Bijinesu ni kansuru Senzai Niizu Chosa-Indo; Kyoiku Shokugyo Bunya [BOP business potential needs survey report-India: Education and vocational training field], March, 2010, p. 21-22
7. Christakis DA. Interactive media use at younger than the age of 2 years: time to rethink the American Academy of Pediatrics guideline? JAMA Pediatr. 2014; 168(5):399-400

8. Anderson DR, Hanson KG. What researchers have learned about toddlers and television. Zero Three. 2013;33(4): 410

9. Roseberry S, Hirsh-Pasek K, Golinkoff RM. Skype me! Socially contingent interactions help toddlers learn language. Child Dev. 2014;85(3):956-970

10. Kucirkova N. iPads in early education: separating assumptions and evidence [published online ahead of print July 8, 2014]. Front Psychol. doi: 10.3389/fpsyg.2014.00715.

11. McQueen A, Cress C, Tothy A. Using a tablet computer during pediatric procedures: a case series and review of the “apps". Pediatr Emerg Care. 2012; 28(7):712-714

12. Radesky JS, Kistin CJ, Zuckerman B, et al. Patterns of mobile device use by caregivers and children during meals in fast food restaurants. Pediatrics. 2014; 133(4). Available at: www.pediatrics.org/ cgi/content/full/133/4/e843

13. Kirkorian HL, Pempek TA, Murphy LA, Schmidt ME, Anderson DR. The impact of background television on parent-child interaction. Child Dev. 2009;80(5):13501359

14. JETRO, Market and its opportunity in India, March, 2012, p.8

15. JETRO, BOP Bijinesu Senzai Niizu Chosa Houkokusho-Indo; Joho Tsushin Gijutsu Bunya [BOP business potential needs survey report-India: Information and telecommunications technology field], March, 2012, p.17

16. Recently SEC (Socio Economic Classification) has been applied to marketing in India to provide a more objective means of categorizing classes. 
Based on the occupation and education of the chief wage earner, consumers are classified into eight groups (A1 to E2). JETRO, Delhi \& Mumbai Style, 2011, p. 14

17. NTT DOCOMO, Mobile Society Research Institute, "Mobile Communication 201213 -White paper on Mobile Society", Chuo Keizaisha Inc, Aug., 2012, p.207. 